\title{
Persea americana: Phenolic profile, Antioxidant potential, Antimicrobial Activity and in silico Prediction of Pharmacokinetic and Toxicological Properties
}

\author{
V. C. K. N. DEUSCHLE* ${ }^{*}$ R. D. CRUZ, V. C. FLORES ${ }^{1}$, L. B. DENARDI'1 , R. A. N. DEUSCHLE, G. G. ROSSI', S. H. ALVES ${ }^{1}$, \\ M. M. A. CAMPOS ${ }^{1}$ AND C. VIANA \\ Postgraduate Program in Pharmaceutical Sciences, Health Science Center, Department of Industrial Pharmacy, ${ }^{1}$ Postgraduate \\ Program in Pharmaceutical Sciences, Health Science Center, Department of Clinical and Toxicological Analysis, Santa Maria \\ Federal University, Santa Maria, RS, Brazil
}

\section{Deuschle et al.: Phenolic Profile from Persea americana Leaves}

\begin{abstract}
The objective of this study was to carry out a phytochemical evaluation of the hydroethanol extract and chloroform, ethyl acetate and butanol fractions of the leaves of Persea americana and correlate with its antioxidant and antimicrobial activities, in order to verify which phytoconstituent is responsible for these activities. In addition, an in silico study of the active constituents identified was carried out to evaluate pharmacokinetic and toxicological properties. The butanol fraction yielded high content of phenolic compounds, total flavonoids, vitamin $C$ and a very high content of rutin $(20.6 \pm 0.5 \mathrm{mg} / \mathrm{g})$ and quercetin $(6.1 \pm 0.1 \mathrm{mg} / \mathrm{g})$. The hydroethanol extract demonstrated $\mathrm{IC}_{50}$ of $6.7 \pm 1.7$ in the 2,2-diphenyl 1-picrylhydrazyl method, ethyl acetate fraction demonstrated greater ability to scavenge $\mathrm{H}_{2} \mathrm{O}_{2}(28.5 \pm 0.1)$ and butanol fraction to reduce $\mathrm{Fe}^{3+}$ to $\mathrm{Fe}^{2+}(55.1 \pm 0.1)$. Significant antifungal activity was found in the hydroethanol extract and the ethyl acetate and butanol fractions (MIC of $32 \mu \mathrm{g} / \mathrm{ml}$ against Candida glabrata and Candida glabrata fluconazole resistant). The ethyl acetate fraction showed antimycobacterial activity with an MIC of $156.25 \mu \mathrm{g} / \mathrm{ml}$ for all species tested. The phytoconstituents identified have no carcinogenic potential but rutin and quercetin might be mutagenic and inhibit cytochrome $\mathrm{P} 450$ isozymes, CYP1A2 and CYP3A4. The results provided a good understanding of the constituents present in the leaves of the plant and their potential for pharmaceutical, food and cosmetics application.
\end{abstract}

Key words: Phenolic compounds, flavonoids, tannins, avocado, free radicals

Persea americana Mill. (Lauracea), popularly known as the avocado, is ill-suited to tropical regions; however, it grows well in temperate regions, especially Central America. Their leaves have been ascribed antitussive, antidiabetic effects, in addition vessel relaxing action, reducing blood pressure and used in seizures and epilepsy in childhood ${ }^{[1-3]}$. Among the activities that have already been described for the leaves of the species, antifungal, antiinflammatory, antioxidant and analgesic activities are the main ones ${ }^{[4,5,1]}$. P. americana contains a variety of compounds with biological activities important for human health. Lima et al. ${ }^{[3]}$ reported the presence of triterpenoids glycosides, coumarins, alkaloids, saponins, tannins, flavonoids, and reducing sugars as constituents in avocado leaves.

The antioxidant potential of the plants has been associated mainly with the presence of phenolic compounds $^{[6]}$. Phenolic compounds that were reported

*Address for correspondence E-mail: vivianenunes1@yahoo.com.br in the leaves of $P$. americana, included, gallic, caffeic, coumaric, ferulic, chlorogenic, resorcylic, sinapic, syringic, vanillic, hydroxybenzoic, protocatechuic and pyrocatechuic acids. Flavonoids found in the leaves were, rutin, quercetin, quercetrin, quercetin-3$O$-arapyranoside, quercetin-3-O- $\beta$-glucopyranoside, quercetin-3-O- $\beta$-D-glucoside, apigenin, luteolin, luteolin-7-O-glucoside, isohamnetin, catechin, epicatechin, kaempferol-3-O-arabinopyranoside and kaempferol-3-O- rhamnopyranoside ${ }^{[6-9]}$.

Many compounds present in plants, which are responsible for the inhibition of bacteria and fungi, can

This is an open access article distributed under the terms of the Creative Commons Attribution-NonCommercial-ShareAlike 3.0 License, which allows others to remix, tweak, and build upon the work non-commercially, as long as the author is credited and the new creations are licensed under the identical terms

Accepted 29 June 2019

Revised 31 March 2019

Received 27 December 2018

Indian J Pharm Sci 2019;81(4):766-775 
constitute an important niche in order to be exploited for the development of new drugs and medications ${ }^{[10]}$. The phenolics, flavonoids, alkaloids, and terpenoids are responsible for the inhibition of microbial growth are among the chemical constituents responsible for the inhibition of microbial growth ${ }^{[11,12]}$. P. americana contains phenolics which could be exploited in relation to these therapeutic benefits ${ }^{[5]}$.

Odo et al. ${ }^{[13]}$ evaluated the acute toxicity and lethality $\left(\mathrm{LD}_{50}\right)$ of methanol and chloroform fractions of leaves of $P$. americana in Wistar rats. The result of this study demonstrated that there was no lethality or any sign of toxicity in animals at 10,100 , and $1000 \mathrm{mg} / \mathrm{kg}$ doses at the end of the first phase of the study. At the end of the second phase of the study, no death or sign of toxicity occurred in groups of animals receiving 1900 and $2600 \mathrm{mg} / \mathrm{kg}$ of both fractions. However, there were deaths and obvious signs of toxicity (slowness, edema in the face and eyes) in the group of rats that received $5000 \mathrm{mg} / \mathrm{kg}$ of either the methanol or the chloroform fraction within $24 \mathrm{~h}$ after administration, which is probably due to the cytotoxic nature of the solvents used. Thus, that study indicated that leaves of $P$. americana were considered safe with a distant risk of acute toxicity.

Thus, the objective of this study was to evaluate phytochemical constitution and determine the antioxidant and antimicrobial activity of the hydroethanol extract and fractions of $P$. americana leaves, in order to identify beneficial effects and the constituents responsible for these effects. In addition, to perform an in silico study of the active constituents identified to understand their pharmacokinetic and toxicological properties.

\section{MATERIALS AND METHODS}

All reagents used in the work were of analytical grade. Standards of rutin, quercetin, catechin, gallic, and chlorogenic acid were acquired from Sigma Chemical Co. (St. Louis, USA). Methanol was of HPLC grade and acquired from Sigma Chemical Co. (St. Louis, USA). Solvents for the extractions, chloroform, ethyl acetate, ethanol, methanol, and $n$-butanol were purchased from Merck (Darmstadt, Germany). Mueller-Hinton broth was obtained from Merck and the oleic acid-albumindextrose-catalase (OADC) from Difco Laboratories (Detroit, Michigan). Aqueous solutions were prepared with ultra-pure water from a Milli-Q Synergy UV system (Merck Millipore, Darmstadt, Germany). High performance liquid chromatography (HPLC-DAD) was performed with the HPLC system (Shimadzu, Kyoto, Japan), Prominence Auto-Sampler (SIL-20A), equipped with Shimadzu LC-20 AT reciprocating pumps connected to the degasser DGU 20A5 with integrator CBM 20A, UV/Vis detector DAD SPDM20A and Software LC solution 1.22 SP and the spectrophotometric analyses was performed on a Shimadzu spectrophotometer (UV-1201).

\section{Plant collection and extraction:}

Leaves of the species were collected in February of 2014 in the city of Cruz Alta, Rio Grande do Sul, Brazil, with the following geographical coordinates, longitude- $-53^{\circ} 36^{\prime} 23^{\prime \prime} \mathrm{W}$; latitude- $-28^{\circ} 38^{\prime} 19^{\prime \prime}$ $\mathrm{S}$; altitude- $452 \mathrm{~m}^{[14]}$. Botanical identification was performed at the Department of Biology, University of Cruz Alta (UNICRUZ), where a voucher specimen has been deposited in the Herbarium of Poisonous and Medicinal plants under the registration code 1109. The species was identified as Persea americana, var. americana.

Fresh leaves were coarsely divided and dried in an oven with air circulation at $45^{\circ}$ for $7 \mathrm{~d}$. The dried plant material was extracted with aqueous ethanol (ethanol:water 70:30, v/v) by maceration as described previously (Deuschle et al. $)^{[15]}$. The hydroethanol extract obtained was further fractionated in separation funnels by sequential extraction using increasingly polar solvents such as chloroform, ethyl acetate, and $n$-butanol (approximately $3 \times 200 \mathrm{ml}$ of each solvent). The organic fractions were concentrated and dried in a rotary evaporator. The hydroethanol extract was lyophilized to obtain dry extract. The extract and fractions were designated as, $P$. americana hydroethanol extract (PAHE), P. americana chloroform fraction (PACL), P. americana ethyl acetate fraction (PAEA) and $P$. americana butanol fraction (PABT).

\section{TLC analysis:}

Phytochemical screening of the extract and fractions was carried out in order to detect essential oil components, terpenoids, saponins, and alkaloids using thin layer chromatograph (TLC) ${ }^{[16]}$. The solid phase consisted of aluminum TLC plates coated with silica-gel 60 with the $\mathrm{F}_{254}$ fluorescent indicator. The mobile phases consisted of specific mixtures of solvents for each class of substances; terpenoids- ethyl acetate:methanol:water (77:15:8); saponins- chloroform:glacial acetic acid:methanol:water $\quad(64: 32: 12: 8)$; alkaloidstoluene:ethyl acetate:diethylamine (70:20:10); 
derived anthracenics- ethyl acetate:methanol:water (100:13:5:10); cardiac glycosides- ethyl acetate:methanol:water (100:13:5:10). Standards were applied for comparison. After elution, results were observed under UV/Vis light (254 and $365 \mathrm{~nm}$ ), and afterwards sprayed with specific reagents (essential oils- sulfuric acid anisaldehyde; terpenoids and saponins- vanillin sulfuric acid; alkaloids- Dragendorff reagent; derived anthracenics- potassium hydroxide and cardiac glycosides- Kedde reagent).

\section{Spectrophotometric analysis:}

Phenolic compounds content was determined using the Folin-Ciocalteau method in alkaline medium, as described by Swaint and Hillis ${ }^{[17]}$. For this, the sample was diluted to a concentration of $1 \mathrm{mg} / \mathrm{ml}$ and the absorbance was measured in triplicate at a wavelength of $750 \mathrm{~nm}$. The total phenol content was expressed as milligrams of gallic acid equivalents per gram of dry plant (mg GAE/g), based on the calibration curve of gallic acid.

Total flavonoid content was established according to the method described by Zhishen et al. ${ }^{[18]}$, using aluminum chloride. The sample was diluted to a concentration of $1 \mathrm{mg} / \mathrm{ml}$ in methanol. The absorbance was then read at $510 \mathrm{~nm}$. Tests were performed in triplicate and the content of flavonoids was determined in milligrams of quercetin equivalents per gram of dry plant (mg QE/g), based on the calibration curve of quercetin.

The condensed tannin determination was carried out using the method described by Morrison et al. ${ }^{[19]}$. The sample was diluted to a concentration of $25 \mathrm{mg} / \mathrm{ml}$ in methanol. The solution was heated at $60^{\circ}$ for $10 \mathrm{~min}$ and the absorbance was determined at $500 \mathrm{~nm}$. Analyses were performed in triplicate. The condensed tannin content was expressed as milligrams of catechin equivalents per gram of dry plant ( $\mathrm{mg} \mathrm{CE} / \mathrm{g}$ ), based on the calibration curve of catechin.

Ascorbic acid content was determined in extracts $(1 \mathrm{mg} / \mathrm{ml})$ using the method of Benderitter et al. ${ }^{[20]}$, based on the reaction with 4-dinitrophenylhydrazine, calculated using a vitamin $\mathrm{C}$ standard curve and expressed in milligrams of ascorbic acid per gram of dry plant (mg AAE/g).

\section{HPLC-DAD analysis:}

Reversed-phase chromatograph analyses were carried out in gradient conditions using C-18 column (4.6× $250 \mathrm{~mm}$ ) packed with $5 \mu \mathrm{m}$ particles. The solvents in the mobile phase were $0.33 \mathrm{M}$ acetic acid in water (A) and methanol $(\mathrm{B})$, and the composition gradient was: $0.0-5 \min 8 \% \mathrm{~B}$; $5-20 \min 20 \% \mathrm{~B} ; 20-30 \min 30 \% \mathrm{~B}$; $30-40$ min $50 \%$ B; $40-50 \min 60 \%$ B; $50-60 \min 70 \%$ B; $60-70 \min 20 \% \mathrm{~B}$; 70-80 min $10 \%$ B as the column washing step ${ }^{[21]}$. The mobile phase and all solutions and samples were filtered through a $0.45 \mu \mathrm{m}$ Millipore membrane filter and then degassed by an ultrasonic bath before use. Quantification was carried out by integration of the peak using external standard method. The flow rate was $0.8 \mathrm{ml} / \mathrm{min}$, the injection volume was $40 \mu 1$. Detected compounds were quantified of $327 \mathrm{~nm}$ at $356 \mathrm{~nm}$. The chromatographic peaks were confirmed by comparing their retention time and DADUV spectra with those of the reference standards. All chromatographic operations were carried out at room temperature $\left(25^{\circ} \pm 1^{\circ}\right)$ and in triplicate.

\section{2,2-Diphenyl 1-picrylhydrazyl (DPPH) radical method:}

The antioxidant capacity was evaluated according to the method previously described by Choi et al. ${ }^{[22]}$. Spectrophotometric analysis was used to determine the inhibition concentration $\left(\mathrm{IC}_{50}\right.$; concentration that offers $50 \%$ inhibition) of the extracts. The extracts were diluted in ethanol in the following concentrations: $250,125,62.5,31.25,62$ and $7.81 \mu \mathrm{g} / \mathrm{ml}$ and $2.5 \mathrm{ml}$ mixed with $1.0 \mathrm{ml}$ of a $0.3 \mathrm{mM}$ DPPH solution in ethanol. After $30 \mathrm{~min}$, the readings were determined at $518 \mathrm{~nm}$. A solution of DPPH $(1 \mathrm{ml}, 0.3 \mathrm{mM})$ dissolved in ethanol $(2.5 \mathrm{ml})$ was used as the negative control. Ascorbic acid was used as positive control, at the same concentrations as the samples. The assay was performed in triplicate and the antioxidant capacity was calculated according to the Eqn. 1, \% inhibition = $100-[($ Abs sample-Abs blank $) \times 100] /$ Abs control, where, Abs sample is the test absorbance; Abs blank is the blank absorbance, and Abs control is the DPPH solution in ethanol absorbance.

\section{Ferric reducing antioxidant power (FRAP assay):}

To $30 \mu 1$ of extraction solution $(25,50,100,250,500$, and $1000 \mu \mathrm{g} / \mathrm{ml}), 90 \mu 1$ distilled water and $900 \mu 1$ of FRAP reagent (acetate buffer $300 \mathrm{mM} / 1,2,4,6$-tripyridyl-Striazine $10 \mathrm{mM} / 1$, and ferric chloride $20 \mathrm{mM} / 1$ in a ratio of 10:1:1) were added. The solutions were mixed and kept at $37^{\circ}$ for $30 \mathrm{~min}$. A standard curve was prepared with ferrous sulphate solution at concentrations of 0.1 , $0.5,1,1.5$, and $2 \mathrm{mM}$. The absorbance was determined at $593 \mathrm{~nm}$. Gallic acid was used as the standard (positive control), at the same concentrations as the samples. 
The reducing power of the extract and the fractions (at the concentrations of $25-1000 \mu \mathrm{g} / \mathrm{ml}$ ) was presented as $\mathrm{mM} \mathrm{Fe}{ }^{2+} / \mathrm{ml}$ extract ${ }^{[23]}$.

\section{Hydrogen peroxide scavenging capacity:}

The ability of the extracts $(50 \mu \mathrm{g} / \mathrm{ml})$ to scavenge hydrogen peroxide was determined according to the method of Ruch et al. ${ }^{[24]}$. Absorbance of hydrogen peroxide at $230 \mathrm{~nm}$ was determined 10 min later against a blank solution containing the phosphate buffer without hydrogen peroxide. Gallic acid was used as the standard (positive control), in the same concentrations as the samples. The percentage of hydrogen peroxide scavenging of the extracts and standard compounds were calculated according to the Eqn. 2, \% scavenged $\left[\mathrm{H}_{2} \mathrm{O}_{2}\right]=[(\mathrm{AC}-\mathrm{AS}) / \mathrm{AC}] \times 100$, where $\mathrm{AC}$ is the absorbance of the control and AS is the absorbance in the presence of the sample (extract) or standard.

\section{Nitric oxide scavenging capacity:}

The scavenging effect of the extracts on nitric oxide radicals was measured according to the method of Sreejayan and $\mathrm{Rao}^{[25]}$. Gallic acid was used as the positive control. For the assay, sodium nitroprusside $(10 \mathrm{mM})$ was mixed with different concentrations of gallic acid or samples $(1,10,25$, and $50 \mu \mathrm{g} / \mathrm{ml})$, incubated for $150 \mathrm{~min}$ and then mixed with $0.5 \mathrm{ml}$ of Griess reagent and measured at $546 \mathrm{~nm}$. In the negative control, the sample was substituted with phosphatebuffered saline. The NO scavenging ability was calculated using the following Eqn. 3, \% scavenging $($ nitric oxide $)=[1-($ A sample $/$ A control $)] \times 100$.

\section{Antibacterial and antifungal activity assays:}

Susceptibility tests were performed according to the Clinical and Laboratory Standards Institute (CLSI) microdilution technique, M07-A $9^{[26]}$ for bacteria, $\mathrm{M} 27-\mathrm{A} 3^{[27]}$ for yeasts and M38-A2 ${ }^{[28]}$ for filamentous fungi, with concentrations ranging from $1000 \mathrm{mg} / \mathrm{ml} \mathrm{a}$ $0.25 \mathrm{mg} / \mathrm{ml}$. The results of the tests were expressed as the minimal inhibitory concentration (MIC).

\section{Fast-growing Mycobacteria (except $M$. smegmatis):}

The susceptibility tests were evaluated by broth microdilution method according to the standard protocol CLSI M24-A2 ${ }^{[29]}$. The extracts were dissolved in dimethyl sulfoxide (DMSO) at a concentration of $10 \mathrm{mg} / \mathrm{ml}$ and diluted in Mueller-Hinton broth to the desired concentrations. To establish the MIC of each extract, different concentrations of the same antimicrobial agent were used in a 1:2 serial dilution series. The inoculum was standardized to MacFarland's 0.5 scale. For the preparation of the final inoculum $\left(5 \times 10^{5} \mathrm{CFU} / \mathrm{ml}\right), 50 \mu 1$ of the bacterial suspension was transferred to a test tube containing $10 \mathrm{ml}$ of MuellerHinton broth. In a sterile microplate titration, $100 \mu \mathrm{l}$ of the inoculum and antibiotic dilutions were added in the same volume. After incubation for $72 \mathrm{~h}$ at $30^{\circ}$, readings were taken from the plates to determine the MIC.

\section{Other microorganisms:}

The inocula were standardized to the MacFarland 0.5 scale in Middlebrook 7H9 medium (MD7H9), supplemented with $10 \%$ OADC and $0.2 \%$ glycerol. For M. smegmatis, the suspension was diluted in MD7H9 to a concentration of $10^{5} \mathrm{CFU} / \mathrm{ml}$. The extracts were dissolved in DMSO at a concentration of $10 \mathrm{mg} / \mathrm{ml}$ and diluted in MD7H9 to the desired concentrations. Susceptibility tests were performed using the broth microdilution method. After incubation at $30^{\circ}$ for $48 \mathrm{~h}$ (M. smegmatis) for $5 \mathrm{~d}$ (M. avium), readings were taken from the plates and the MIC was determined. To verify the presence of microorganism growth, the dye 2,3,5-triphenyltetrazolium chloride (TTC-Sigma) was used. The MIC for use in microbiological assays is considered the lowest concentration of sample that can produce visible inhibition of microorganism growth $^{[29,30]}$. Negative controls of all assays consisted of dilutions of extract/fractions in the culture medium at the same assay concentrations, but without inoculum.

\section{In silico toxicology and pharmacological properties:}

The LAZAR ${ }^{[31]}$ and AdmetSAR ${ }^{[32]}$ open source softwares were used to predict the toxicity and pharmacokinetic properties of chlorogenic acid, rutin, and quercetin, which were the constituents identified.

\section{Statistical analysis:}

The results of the determinations were subjected to analysis of variance (ANOVA) followed by post hoc multiple comparison using the Tukey test $(p \leq 0.05)$. The analyses were performed using GraphPad Prism for Windows, version 5.03 (GraphPad Software, San Diego, CA, USA).

\section{RESULTS AND DISCUSSION}

With the results obtained in this study, capacities of different solvents used to extract the phenolic compounds, which directly influenced the antioxidant and antimicrobial activities was tested. In general, more polar solvents have a greater potential in extracting 
such compounds. The TLC analysis demonstrated the presence of saponins and anthracenic derivatives for PAHE and PABT and only anthracenic derivatives for PAEA. The other extracts tested negative for the tested compounds. The total phenolic content, total flavonoids, condensed tannins, vitamin $\mathrm{C}$ content are shown in Table 1. The highest content of flavonoids and polyphenols was observed in PABT. For the determination of condensed tannins, the highest value was found in PACL. The presence of tannins, flavonoids, and saponins may be associated with antidiarrheal and antispastic effects already described for $P$. americana leaves in traditional medicine ${ }^{[13]}$. Moreover, phenolic compounds such as flavonoids and tannins are secondary metabolites that are related to the antioxidant activities of plants $^{[33]}$.

Ascorbic acid (vitamin C) is a potent inhibitor of singlet oxygen, superoxide anion, hydroxyl radical, hydrogen peroxide and reactive nitrogen species ${ }^{[34,35]}$. All samples showed different levels of vitamin $\mathrm{C}$, but the butanol fraction presented the highest amount. The presence of vitamin $\mathrm{C}$ in the $P$. americana leaf extract also contributed to the antioxidant activity of this sample, determined in this study using DPPH, FRAP, $\mathrm{H}_{2} \mathrm{O}_{2}$ and nitric oxide scavenging methods. Ethyl acetate is an intermediate polarity solvent; this fraction contained lower levels of polyphenols. In the chloroform fraction, none of the compounds were identified since as this was the most non-polar solvent ${ }^{[36]}$.

The extracts and fractions were analysed using HPLCDAD for the determination of phenolic compounds. The results indicated the presence of the following compounds with retention times (Rt). PAHEchlorogenic acid (20.208; peak 1), rutin (32.548; peak 2) and quercetin (40.10; peak 3 ); PAEA- chlorogenic acid (20.194; peak 1), rutin (32.548; peak 2) and quercetin (41.02; peak 3); PABT- chlorogenic acid (20.185; peak 1$)$, rutin $(\mathrm{Rt}=32.487$; peak 2$)$ and quercetin (40.975; peak 3, fig. 1), and in PACL, no compounds were found. The quantification of chlorogenic acid, quercetin, and rutin by HPLC-DAD based on the reference standards is shown in fig. 1 . The presence of chlorogenic acid, rutin and quercetin in the leaves of P. americana was reported by other authors ${ }^{[6-9]}$.

The $\mathrm{IC}_{50}$ values of DPPH and $\mathrm{H}_{2} \mathrm{O}_{2}$ scavenging activity are shown in Table 1. Reducing power of the extracts was assessed based on their ability to reduce $\mathrm{Fe}^{3+}$ to $\mathrm{Fe}^{2+}$, as presented in fig. 2. NO scavenging activity is presented in Table 2 . In relation to antioxidant capacity determined by the DPPH assay (Table 1), it was observed that all samples showed the ability to reduce $\mathrm{DPPH}$ radicals. The lowest $\mathrm{IC}_{50}$ was found for PAHE $(6.73 \mu \mathrm{g} / \mathrm{ml})$, and was very close to the $\mathrm{IC}_{50}$ of vitamin $\mathrm{C}$, which was used as the standard $(5.08 \mu \mathrm{g} / \mathrm{ml})$.

The reducing power of the extract and the fractions was determined by the FRAP method, which demonstrates the capacity to reduce $\mathrm{Fe}^{3+}$ to $\mathrm{Fe}^{2+}$, thereby directly measuring the concentration of antioxidant electron donors ${ }^{[34,37]}$. The butanol fraction exhibited greater capability than gallic acid, the positive standard. The results for the hydroethanol extract and ethyl acetate fraction were similar to that of the standard, while the chloroform fraction showed the least reducing power (fig. 2). Table 2 shows that the extracts were
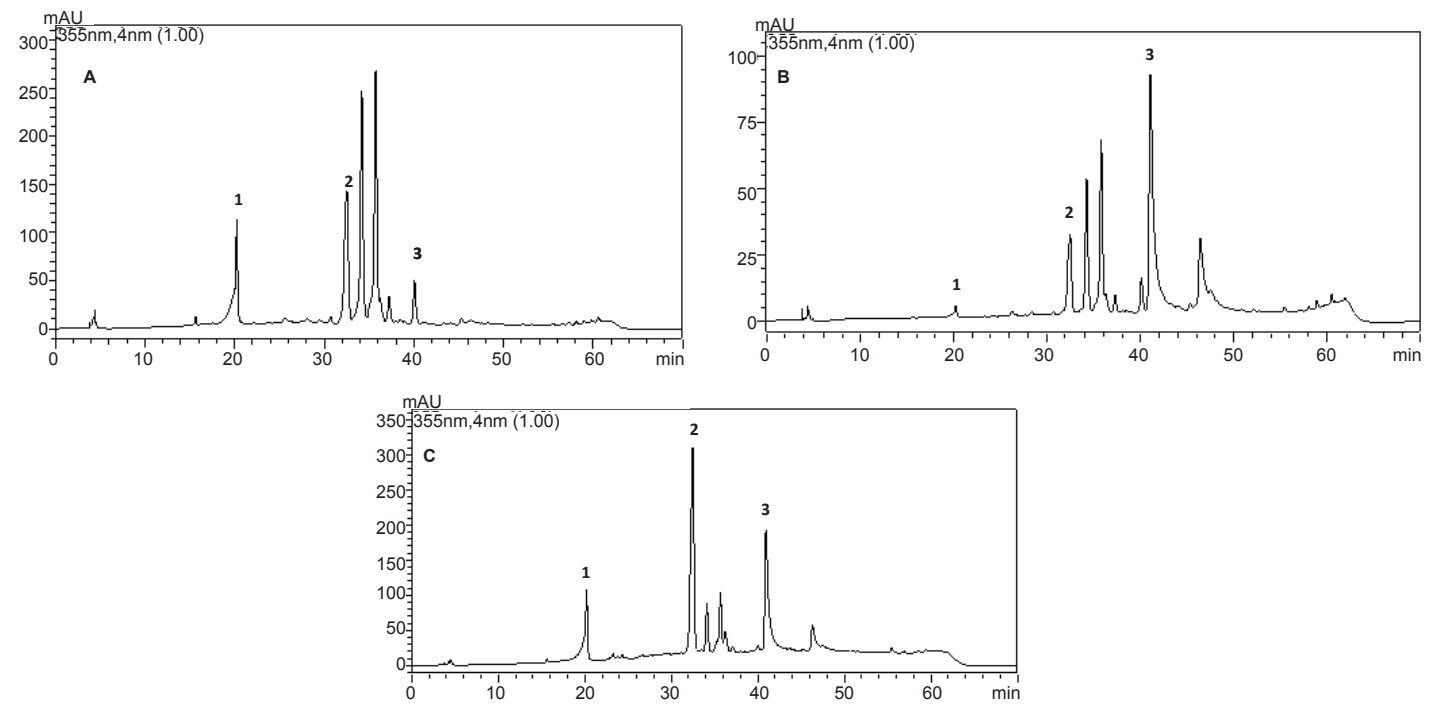

Fig. 1: High performance liquid chromatograms from the leaves of Persea americana A. hydroethanolic extract (PAHE), B. ethyl acetate extract (PAEA), C. butanol extract (PABT). 1. chlorogenic acid, 2. rutin and 3. quercetin 
TABLE 1: TOTAL PHENOLS, FLAVONOIDS, CONDENSED TANNINS, VITAMIN C AND ANTIOXIDANT ACTIVITY OF PERSEA AMERICANA

\begin{tabular}{|c|c|c|c|c|c|c|}
\hline Extract & $\begin{array}{l}\text { Total phenols } \\
(\mathrm{mg} \mathrm{GAE} / \mathrm{g}) \pm \mathrm{SE}^{*}\end{array}$ & $\begin{array}{l}\text { Total flavonoids } \\
(\mathrm{mg} \mathrm{QE} / \mathrm{g}) \pm \mathrm{SE}^{*}\end{array}$ & $\begin{array}{c}\text { Condensed } \\
\text { tannins }(\mathrm{mg} \mathrm{CAE} / \mathrm{g}) \pm \mathrm{SE}^{*}\end{array}$ & $\begin{array}{l}\text { Ascorbic acid } \\
(\mathrm{mg} \mathrm{AAE} / \mathrm{g}) \pm \mathrm{SE}^{*}\end{array}$ & $\begin{array}{c}\mathrm{IC}_{50} \mathrm{DPPH} \\
(\mu \mathrm{g} / \mathrm{ml}) \pm \mathrm{SE}^{*}\end{array}$ & $\begin{array}{l}\text { Scavenging } \\
\mathrm{H}_{2} \mathrm{O}_{2}(\%) \pm \mathrm{SE}^{*}\end{array}$ \\
\hline PAHE & $99.4 \pm 1.2^{\mathrm{a}}$ & $42.5 \pm 1.9^{a}$ & $69.7 \pm 1.5^{\mathrm{a}}$ & $5.9 \pm 0.1^{\mathrm{a}}$ & $6.7 \pm 1.7^{a}$ & $5.7 \pm 0.1^{\mathrm{a}}$ \\
\hline PACL & $19.7 \pm 1.3^{b}$ & $9.3 \pm 1.2^{b}$ & $86.7 \pm 1.3^{b}$ & $2.1 \pm 0.1^{b}$ & $19.0 \pm 1.5^{b}$ & $3.4 \pm 0.2^{b}$ \\
\hline PAEA & $85.2 \pm 0.1^{c}$ & $54.9 \pm 1.8^{c}$ & $22.9 \pm 0.8^{c}$ & $5.4 \pm 0.1^{\mathrm{a}}$ & $19.7 \pm 0.8^{c}$ & $28.5 \pm 0.1^{c}$ \\
\hline PABT & $127.0 \pm 0.1^{d}$ & $93.6 \pm 0.7^{d}$ & $22.3 \pm 0.4^{c}$ & $11.3 \pm 0.7^{c}$ & $14.2 \pm 3.2^{\mathrm{d}}$ & $8.0 \pm 0.3^{d}$ \\
\hline AAE & ND & ND & ND & ND & $5.0 \pm 0.4^{e}$ & ND \\
\hline GAE & ND & ND & ND & ND & ND & $4.5 \pm 0.1^{\mathrm{e}}$ \\
\hline
\end{tabular}

*Results are expressed as mean \pm standard error $(\mathrm{SE})$ of three determinations. GAE- gallic acid equivalents, QE- quercetin equivalents, CAEcatechin equivalents, AAE- ascorbic acid equivalents, ND- not determined. Means marked with different letters are significantly different $(\mathrm{p}<0.05)$ in the same column. PAHE- $P$. americana hydroethanol extract, PACL- $P$. americana chloroform fraction, PAEA- $P$. americana ethyl acetate fraction, and PABT- $P$. americana butanol fraction

\section{TABLE 2: NO SCAVENGING CAPACITY OF PERSEA AMERICANA}

\begin{tabular}{lccccc}
\hline $\begin{array}{l}\text { Extract/concentration } \\
(\mu \mathrm{g} / \mathrm{ml})\end{array}$ & $\mathrm{GA}(\%) \pm \mathrm{SE}^{*}$ & $\mathrm{PAHE}(\%) \pm \mathrm{SE}^{*}$ & $\mathrm{PACL}(\%) \pm \mathrm{SE}^{*}$ & $\mathrm{PAEA}(\%) \pm \mathrm{SE}^{*}$ & PABT $(\%) \pm \mathrm{SE}^{*}$ \\
\hline 1 & $94.5 \pm 0.1^{\mathrm{a}}$ & $28.3 \pm 0.4^{\mathrm{a}}$ & $45.4 \pm 0.4^{\mathrm{a}}$ & $45.4 \pm 0.4^{\mathrm{a}}$ & $51.6 \pm 0.3^{\mathrm{a}}$ \\
10 & $79.3 \pm 4.0^{\mathrm{b}}$ & $35.6 \pm 0.1^{\mathrm{b}}$ & $48.4 \pm 3.6^{\mathrm{b}}$ & $46.6 \pm 0.2^{\mathrm{b}}$ & $55.0 \pm 0.1^{\mathrm{b}}$ \\
25 & $77.5 \pm 1.1^{\mathrm{c}}$ & $40.5 \pm 0.5^{\mathrm{c}}$ & $49.3 \pm 1.6^{\mathrm{c}}$ & $47.5 \pm 1.7^{\mathrm{a}}$ & $55.1 \pm 0.2^{\mathrm{c}}$ \\
50 & $78.2 \pm 4.1^{\mathrm{d}}$ & $38.5 \pm 0.6^{\mathrm{d}}$ & $49.9 \pm 0.3^{\mathrm{c}}$ & $44.7 \pm 1.8^{\mathrm{c}}$ & $55.1 \pm 0.3^{\mathrm{d}}$ \\
\hline
\end{tabular}

*Results are expressed as mean \pm standard error (SE) of three determinations. Means marked with different letters are significantly different $(p<0.05)$ in the same column. GA is gallic acid

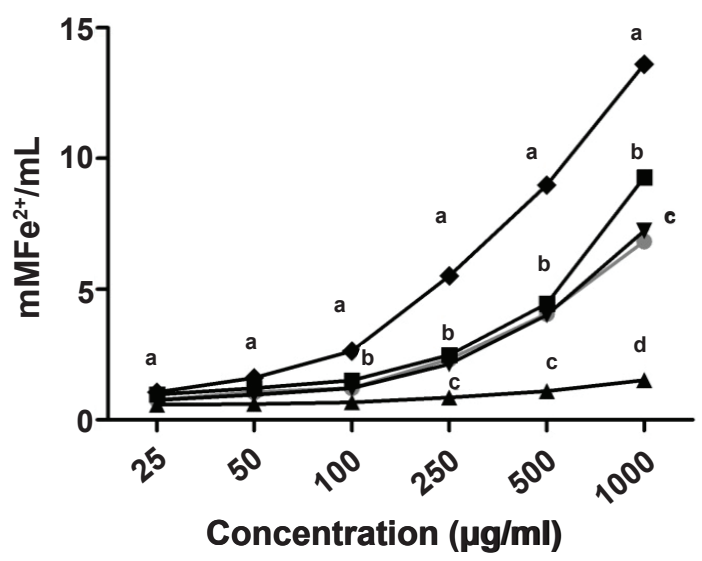

Fig. 2: FRAP activity of Persea americana extract and fractions and gallic acid

Ferric Reducing antioxidant power (FRAP) activity of PABT

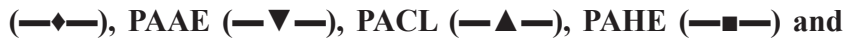
GAA (- - ), each value is expressed as means \pm standard error $(n=3)$. Different letters represent significant differences $(\mathbf{p}<\mathbf{0 . 0 5})$

significantly less active than the gallic acid standard in the nitric oxide scavenging capacity test, but the butanol fraction at the higher concentration tested $(50 \mu \mathrm{g} / \mathrm{ml})$ showed a nitric oxide scavenging capacity of $58 \%$. The ability of the extracts to scavenge $\mathrm{H}_{2} \mathrm{O}_{2}$ radicals was also tested (Table 1 ). This test results showed that PAHE was similar to the standard, PABT was slightly higher and PAEA exhibited activity significantly greater than that of the standard. The demonstrated antioxidant capacity could be due to the presence of phenolic compounds identified and quantified (especially rutin and quercetin). Phenolic compounds are considered to be strong natural antioxidants, due the redox capacity of their hydroxyl groups, thereby being able to remove free radicals ${ }^{[38,39]}$.

Table 3 showed the results of antifungal screening. Good antifungal activity was observed for PAHE, with MIC $32 \mu \mathrm{g} / \mathrm{ml}$ for Candida glabrata fluconazoleresistant, $C$. glabrata and $C$. albicans; PAEA and PABT also gave MIC of $32 \mu \mathrm{g} / \mathrm{ml}$ for C. glabrata and $C$. glabrata fluconazole-resistant. In addition, the results indicated that PAEA presented a MIC of $128 \mu \mathrm{g} / \mathrm{ml}$ for C. parapsiloisis and Cryptococcus neoforms and PABT, a MIC of $128 \mu \mathrm{g} / \mathrm{ml}$ for C. neoforms and Sacharomyces cerevisiae. The remaining antifungal MICs were very high and not relevant. According to Cushinie and $\mathrm{Lamb}^{[12]} \mathrm{MIC}$ values lower than or equal to $100 \mu \mathrm{g} / \mathrm{ml}$ for antimicrobial activity related to the presence of flavonoids are considered remarkable. The results obtained for P. americana are within this range. Flavonoids have been known to have antimicrobial activity, and the presence of rutin and quercetin in the extracts likely contributed to this activity ${ }^{[40]}$. In a study by Araruna et $a l .{ }^{[40]}$, the antifungal activity of rutin presented an MIC of $32 \mu \mathrm{g} / \mathrm{ml}$ against three Candida species 
(C. albicans, C. krusei, and C. tropicalis). In our study, the presence of this compound also contributed to such inhibition. The mechanism of antifungal activity of flavonoids is probably due to the ability to complex with extracellular and soluble proteins of the fungal cell wall[41].

These extracts had low MICs, which is extremely important, since many fungi are resistant to most antifungals. Infections caused by Candida species have increased significantly in the last $30 \mathrm{y}$, especially in immunocompromised patients ${ }^{[42]}$. C. albicans is the most frequently isolated pathogen in patients in this condition $^{[42,43]}$, with high morbidity and mortality ${ }^{[44]}$. Although $C$. albicans is the most frequently isolated species, there has been a marked increase in the frequency of other species such as $C$. glabrata, which stands out due to its lower sensitivity to antifungal agents, mainly to the azoles ${ }^{[45]}$.

Bacteria used in antibacterial screening activity were Enterococcus faecalis ATCC 91299, Escherichia coli ATCC 5922, Klebsiella pneumoniae ATCC 700603, Pseudomonas aeruginosa ATCC 27853, Salmonella pullorum ATCC 9140 and Staphylococcus aureus ATCC 29213. However, none of the compounds showed activity until the highest concentration tested, which was $1280 \mu \mathrm{g} / \mathrm{ml}$. Although there have been studies that correlated antibacterial activity with the polyphenol and total flavonoid contents, this is also dependent on factors such as the amounts of these compounds present in the extracts and the target microorganism ${ }^{[46,47]}$. Moreover, Pereira et al. ${ }^{[48]}$ demonstrated that rutin isolated from the plant Solanum palinacanthum Dunal (Solanaceae) does not inhibit the growth of Staphylococcus aureus, confirming the negative results, obtained in present study.

The results of the antimycobacterial activity assessment are summarized in Table 4. Non-tubercular mycobacteria are generally ubiquitous microorganisms in the environment and, from a clinical point of view, are important opportunistic pathogens for which the therapeutic arsenal is restricted ${ }^{[49]}$. The best activity exhibited against all species tested was by the ethyl acetate fraction (MIC $156.25 \mu \mathrm{g} / \mathrm{ml}$ ). According to Tosun et al. ${ }^{[50]}$, a plant extract is considered active against mycobacteria, which can prevent growth at a concentration below $200 \mu \mathrm{g} / \mathrm{ml}$. As Santhosh and Suriyanarayanan ${ }^{[11]}$ have stated, plant extracts with high concentrations of flavonoids, particularly those belonging to the class of flavones and flavonols (quercetin), have demonstrated antimycobacterial activity. The results obtained in our study confirm some previous data regarding $P$. americana phenolic compounds. However, literature does not show data comparing the extracts obtained with the solvents used in our study.

Using the LAZAR tool (Table 5), it was observed that these substances are not likely to have carcinogenic potential, however, rutin and quercetin could be mutagenic. In addition, quercetin penetrates blood brain barrier, which could be related to the effects on the central nervous system. According to Table 6, the data related to the search through the AdmetSAR tool showed that all the substances studied showed intestinal absorption and do not inhibit P-glycoprotein. P-glycoprotein acts as a pump in the efflux of drugs and xenobiotics and participates in the processes of the

TABLE 3: MIC VALUES FOR PERSEA AMERICANA FRONT AGAINST YEAST AND FILAMENTOUS FUNGI

\begin{tabular}{lccccc}
\hline Strains & ATCC & PAHE & PACL & PAEA & PABT \\
\hline Candida tropicalis & $\mathrm{Cl}^{*}$ & $\geq 1280$ & $\geq 1280$ & $\geq 1280$ & $\geq 1280$ \\
Candida parapsilosis & 22018 & 256 & 1280 & 128 & 256 \\
Candida glabrata & 2001 & 32 & 512 & 32 & 32 \\
Candida glabrata $-\mathrm{FR}$ & $\mathrm{Cl}^{*}$ & 32 & 512 & 32 & 32 \\
Candida dubliniensis & $\mathrm{CBS} 7987$ & 256 & $\geq 1280$ & 256 & 512 \\
Candida dubliniensis - FR & $\mathrm{Cl}^{*}$ & 256 & $\geq 1280$ & 256 & 512 \\
Candida albicans & 14053 & 32 & $\geq 1280$ & 256 & 512 \\
Cryptococcus neoformans & 90012 & 256 & 1280 & 128 & 128 \\
Sacharomyces cerevisae & 2601 & 512 & $\geq 1280$ & $\geq 1280$ & 128 \\
Candida guilliermondii & $\mathrm{Cl}^{*}$ & 512 & 1280 & 256 & 256 \\
Aspergillus fumigatus & $\mathrm{Cl}^{*}$ & $\geq 1280$ & $\geq 1280$ & $\geq 1280$ & $\geq 1280$ \\
Aspergillus flavus & $\mathrm{Cl}^{*}$ & $\geq 1280$ & $\geq 1280$ & $\geq 1280$ & $\geq 1280$ \\
\hline
\end{tabular}

${ }^{*} \mathrm{Cl}$ - clinical isolate; FR- fluconazole-resistant, MIC- minimum inhibitory concentration 
TABLE 4: MIC VALUES FOR PERSEA AMERICANA FRONT AGAINST MYCOBACTERIAL NON TUBERCULOSUS (MNT)

\begin{tabular}{lccccc}
\hline Strains & ATCC & PAHE & PACL & PAEA & PABT \\
\hline M. abscessos & 19977 & $>2500$ & 625 & 156.25 & 312.5 \\
M. fortuitum & 6841 & $>2500$ & 12500 & 156.25 & 625 \\
M. Massiliense & 48898 & $>2500$ & 12500 & 156.25 & 312.5 \\
M. smegmatis & 700084 & 2500 & 2500 & 156.25 & 12500 \\
M. avium & LR541CDC & 2500 & 12500 & 156.25 & 625 \\
\hline
\end{tabular}

MIC- minimum inhibitory concentration

TABLE 5: PREDICTION OF TOXITY USING LAZAR

\begin{tabular}{lccc}
\hline \multirow{2}{*}{ Evaluated parameters } & \multicolumn{3}{c}{ Compounds } \\
\cline { 2 - 4 } & Chlorogenic acid & Ruin & Quercetin \\
\hline Blood brain barrier penetration (Human) & Non-penetrating & Non-penetrating & Penetrating \\
Carcinogenicity (rat) & Non-carcinogenic & Non-carcinogenic & Non-carcinogenic \\
Carcinogenicity (rodents) & Non-carcinogenic & Non-carcinogenic & Non-carcinogenic \\
Mutagenicity (Salmonella typhimurium) & Non-mutagenic & Mutagenic & Mutagenic \\
\hline
\end{tabular}

TABLE 6: PREDICTION OF TOXITY AND PHARMACOKINETIC PROPERTIES USING ADMETSAR

\begin{tabular}{lccc}
\hline \multirow{2}{*}{ Evaluated parameters } & \multicolumn{2}{c}{ Compounds } \\
\cline { 2 - 4 } Human intestinal absorption & Chlorogenic acid & Ruin & Quercetin \\
P-glycoprotein & Positive & Positive & Positive \\
CYP450 2C9 Substrate & Non-inhibitor & Non-inhibitor & Non-inhibitor \\
CYP450 2D6 Substrate & Non-substrate & Non-substrate & Non-substrate \\
CYP450 3A4 Substrate & Non-substrate & Non-substrate & Non-substrate \\
CYP450 1A2 Inhibitor & Non-substrate & Non-substrate & Non-substrate \\
CYP450 2C9 Inhibitor & Non-inhibitor & Inhibitor & Inhibitor \\
CYP450 2D6 Inhibitor & Non-inhibitor & Non-inhibitor & Non-inhibitor \\
CYP450 2C19 Inhibitor & Non-inhibitor & Non-inhibitor & Non-inhibitor \\
CYP450 3A4 Inhibitor & Non-inhibitor & Non-inhibitor & Non-inhibitor \\
\hline
\end{tabular}

absorption, distribution, metabolism and excretion of $\operatorname{drugs}^{[52]}$.

It has also been found that rutin and quercetin could be inhibitors of CYP1A2 and CYP3A4 isozymes of cytochrome P450. Cytochrome P450 corresponds to the main family of enzymes related to the metabolism of drugs and xenobiotics. Regulation of these enzymes occurs in various forms, for example, genetic variation and xenobiotic or endogenous induction and repression (as for example, by cytokines and hormones) ${ }^{[53,54]}$.

The results demonstrated that the secondary metabolites presented in $P$. americana leaves have antioxidant and antimicrobial activities. For this reason, the present study provides a basis for the use of this extract and its fractions in mycobacterial and fungal infections, mainly against Candida species and also as free radical scavengers, important as preventive of various disorders related to oxidative damage.

\section{Acknowledgments:}

The authors gratefully acknowledge the contributions of Prof. Dr. Margareth Linde Athayde (in memoriam) in the development of this research.

\section{Conflict of interest:}

Authors declare no conflicts of interest.

\section{REFERENCES}

1. Larijani K, Rustaiyan A, Azar PA, Taban S. Composition of essential oil of leaves of Persea americana cultivated in Iran. Chem Nat Comp 2010;46:489-90.

2. Adisa, JO, Ajayi Y, Egbujo EC. Histopathologic effect of Persea americana aqueous leaves extract on the liver and kidney of weaner rabbits (California Species). Int J Morphol 2011;29:1384-7.

3. Lima CR, Vasconcelos CF, Costa-Silva JH, Maranhão CA, Costa J, Batista TM, et al. Anti-diabetic activity of extract 
from Persea americana Mill. leaf via the activation of protein kinase B (PKB/Akt) in streptozotocin-induced diabetic rats. J Ethnopharmacol 2012;141:517-25.

4. Lee TH, Tsai YF, Huang TT, Chen PY, Liang WL, Lee CK. Heptadecanols from the leaves of Persea americana Mill. var. Americana. Food Chem 2012;132:921-4.

5. Yasir M, Das S, Kharya MD. The phytochemical and pharmacological profile of Persea americana Mill. Pharmacogn Rev 2010;4(7):77-84.

6. Vieites RL, Daiuto ER, Fumes JGF. Capacidade antioxidante e qualidade pós-colheita de abacate 'Fuerte'. Rev Bras Frutic 2012;34:336-48.

7. Zhang Z, Huber DJ, Rao J. Antioxidant systems of ripening avocado (Persea americana Mill.) fruit following treatment at the preclimacteric stage with aqueous 1 methylcyclopropene. Postharvest Biol Tecnol 2013;76:58-64.

8. Ding $H$, Chin YW, Kinghorn AD, D'Ambrosio SM. Chemopreventive characteristics of avocado fruit. Semin Cancer Bio 2007; 17:386-94.

9. Owolabi M, Jaja SI, Coker H. Bioactivity of the phytoconstituents of the leaves of Persea americana. J Med Plants Res 2010;4:1130-5.

10. Wang W, Bostic TR, Gu L. Antioxidant capacities, procyanidins and pigments in avocados of different strains and cultivars. Food Chem 2010;122:1193-8.

11. Jiménez P, García P, Bustamante A, Barriga A, Robert P. Thermal stability of oils added with avocado (Persea americana cv. Hass) or olive (Olea europaea cv. Arbequina) leaf extracts during the French potatoes frying. Food Chem 2017;221:123-9.

12. Cushinie TP, Lamb AJ. Recent advances in understanding the antibacterial properties of flavonoids. Int J Antimicrob Agents 2011;38(2):99-107.

13. Odo CE. Anti-motility and reductions in the concentrations of gut electrolytes: Bases for the anti-spastic use of the leaves of Persea americana in folk medicine. J Pharm Res 2013;6:33641.

14. Brazil. Brazilian Institute of Geography and Statistics - BIGS. [cited 2016 Jul 20] Available from: http://www.brasil.gov. br/meio-ambiente/2011/11/ibge-disponibilizacoordenadas-e altitudes-para-21.304-localidades-brasileiras.

15. Deuschle VCKN, Brusco I, Piana M, Faccin H, de Carvalho LM, Oliveira SM, et al. Persea americana Mill. crude extract exhibits antinociceptive efect on UVB radiation-induced skin injury in mice. Inflammopharmacol 2019;27(2):323-38.

16. Wagner H, Bladt S. Plant Drug Analysis. A Thin Layer Chromatography Atlas. 2nd ed. Berlin Heidelberg: SpringerVerlag; 1996.

17. Swaint T, Hillis WE. The phenolic constituents of Prunus domestica I. The quantitative analysis of phenolic constituents. J Sci Food Agric 1959;10:63-8.

18. Zhishen J, Mengcheng T, Jianming W. The determination of flavonoid contents of mulberry and their scavenging effects on superoxide radicals. Food Chem 1999;64:555-9.

19. Morrison M, Asiedu EA, Stuchbury T, Powel AA. Determination of lignin and tannin contents of cowpea seed coats. Ann Bot 1995;76:287-90.

20. Benderitter M, Maupoil V, Vergely C, Dalloz F, Briot F, Rochette L. Studies by electron paramagnetic resonance of the importance of iron in the hydroxyl scavenging properties of ascorbic acid in plasma: Effects of iron chelators. Fundam Clin Pharmacol 1998;12:510-6.
21. Evaristo IM, Leitão MC. Identificação e quantificação por DAD-HPLC, da fração fenólica contida em folhas de Quercus súber L. Silva Lusit. 2001;9:135-41.

22. Choi CW, Kim SC, Hwang SS, Choi BK, Ahn HJ, Lee MY, et al. Antioxidant activity and free radical scavenging capacity between Korean medicinal plants and flavonoid by assayguided comparison. Plant Sci 2002;163:1161-8.

23. Benzie IF, Strain JJ. The ferric reducing ability of plasma (FRAP) as a measure of "antioxidant power": The FRAP Assay. Anal Biochem 1996;239:70-6.

24. Ruch RJ, Cheng, SJ, Klaunig JE. Prevention of cytotoxicity and inhibition of intracellular communication by antioxidant catechins isolated from Chinese green tea. Carcinogenesis 1989;10:1003-8.

25. Sreejayan N, Rao MN. Nitric oxide scavenging by curcuminoids. J Pharm Pharmacol 1997;49:105-7.

26. Clinical and Laboratory Standards Institute. Performance standards for antimicrobial susceptibility testing. CLSI approved standard M07A9. Available from: https://clsi.org/ standards/products/microbiology/documents/m07/.

27. Clinical and Laboratory Standards Institute. Performance standards for antimicrobial susceptibility testing. CLSI approved standard M27-A3. Available from: https://clsi.org/ standards/products/microbiology/documents/m27/.

28. Clinical and Laboratory Standards Institute. Performance standards for antimicrobial susceptibility testing. CLSI approved standard M38-A2. Available from: https://clsi.org/ standards/products/microbiology/documents/m38/.

29. Clinical and Laboratory Standards Institute. Susceptibility testing of mycobacteria, Nocardiae, and other Aerobic Actinomycetes; Approved Standard - Second edition. CLSI document M24-A2. Available from: https:/clsi.org/standards/ products/microbiology/documents/m24/.

30. Franzblau SG, Witzig RS, McLaughlin JC, Torres P, Madico G, Hernandez A, et al. Rapid, low-technology MIC determination with clinical Mycobacterium tuberculosis isolates by using the microplate Alamar Blue assay. J Clin Microbiol 1998;36:362-6.

31. Guerra LR, Souza AML, Côrtes JA, Lione VOF, Castro HC, Alves GG. Assessment of predictivity of volatile organic compoundscarcinogenicity and mutagenicity by freeware in silico models. Regul Toxicol Pharmacol 2017;91:1-8.

32. Chinnasamy $\mathrm{P}$, Arumugam R. In silico prediction of anticarcinogenic bioactivities of traditional anti-inflammatory plants used by tribal healers in Sathyamangalam wildlife Sanctuary, India. Egypt J Basic Appl Sci 2018;5:265-79.

33. Milani LIG, Terra NN, Fries LLM, Cichoski AJ, Rezer APS, Backes AM, et al. In vitro antioxidant and antimicrobial properties of persimmon (Diospyros kaki L. cv. Rama Forte) extracts. Braz J Food Technol 2012;5:118-24.

34. Sucupira NR, Silva AB, Pereira G, Costa JN. Methods for measuring antioxidant activity of fruits. Cient Ciênc Biol Saúde. 2012;14:263-9.

35. Adetuyi F O, Ibrahim T A. Effect of fermentation time on the phenolic, flavonoid and vitamin $\mathrm{C}$ contents and antioxidant activities of okra (Abelmoschus esculentus) seeds. Niger Food J 2014;32:128-37.

36. Martins CR, Lopes WA, Andrade JB. Organic compound solubility. Quim Nova 2013;36:1248-55.

37. Wang M, Zheng Y, Khuong T, Lovatt CJ. Developmental differences in antioxidant compounds and systems in 
normal and small-phenotype fruit of 'Hass' avocado (Persea americana Mill.). Sci Hortic 2016;206:15-23.

38. Amic D, Davidovic-Amic D, Beslo D, Trinajstic N. Structureradical scavenging activity relationship of flavonoids. Croat Chem Acta 2003;76:55-61.

39. Materska M, Perucka I. Antioxidant activity of the main phenolic compunds isolated from hot pepper fruit (Capsicum annuum L.). J Agric Food Chem 2005;53:1750-6.

40. Araruna MKA, Brito SA, Morais-Braga MFB, Santos KKA, Souza T M, Leite TR, et al. Evaluation of antibiotic \& antibiotic modifying activity of pilocarpine E rutin. Indian J Med Res 2012;135:252-4.

41. Arif T, Bhosale JD, Kumar N, Mandal TK, Bendre RS, Lavekar GS, et al. Natural products: Anti - fungal agents derived from plants. J Asian Nat Prod Res 2011;81:283-311.

42. Cossu A, Wang MS, Chaudhari A, Nitin N. Antifungal activity against Candida albicans of starch pickering emulsion with thymol or amphotericin B in suspension and calcium alginate films. Int J Pharm 2015;493:233-42.

43. Wang TM, Shi GX, Shao J, Wu D, Yan Y, Zhang M, et al. In vitro antifungal activity of baicalin against Candida albicans biofilms via apoptotic induction. Microb Pathog 2015;87:219.

44. Salari S, Khosravi AR, Mousavi SA, Nikbakht-Brojeni GH. Mechanisms of resistance to fluconazole in Candida albicans clinical isolates from Iranian HIV infected patients with oropharyngeal candidiasis. J Med Micol 2016;26:35-41.

45. Soares IH, Loreto ES, Rossato L, Mario DN, Venturini TP, Baldissera $\mathrm{F}$, et al. In vitro activity of essential oils extracted from condiments against fluconazole-resistant and -sensitive Candida glabrata. J Med Mycol 2015;25:213-7.

46. Calderón-Oliver M, Escalona-Buendía HB, Medina-Campos
ON, Pedraza Chaveri J, Pedroza-Islas R, Ponce-Alquicira E. Optimization of the antioxidant and antimicrobial response of the combined effect of nisin and avocado by products. Food Sci Technol 2016;65:46-52.

47. Windsten PC, Cruz CD, Fletcher GC, Pajak MA, McGhie TK. Tannins and extracts of fruit byproducts: antibacterial activity against foodborne bacteria and antioxidant capacity. J Agric Food Chem 2014;62:11146-56.

48. Pereira AC, Oliveira DF, Silva GH, Figueiredo HCP, Cavalheiro AJ, Carvalho DA, et al. Identification of the antimicrobial substances produced by Solanum palinacanthum (Solanaceae). Ann Brazilian Acad Sci. 2008;80:427-32.

49. Qvist T, Pressler T, Hoiby N, Katzenstein TL. Shifting paradigms of nontuberculous mycobacteria in cystic fibrosis. Respir Res 2014;15:1-6.

50. Tosun F, Kizilay CA, Sener B, Vural M, Palittapongarnpim P. Antimycobacterial screening of some Turkish plants. J Ethnopharmacol 2004;95:273-5.

51. Santhosh RS, Suriyanarayanan B. Plants: a source for new antimycobacterial drugs. Planta Med 2014;80(1):9-21.

52. Amin L. P glycoprotein inhibition for optimal drug delivery. Drug Targets Insights 2013;7:27-34.

53. Zanger UM, Turpeinen M, Klein K, Schwab M. Functional pharmacogenetics/genomics of human cytochromes P450 involved in drug biotransformation. Anal Bioanal Chem 2008;392:1093-108.

54. Zanger UM, Schwab M. Cytochrome P450 enzymes in drug metabolism: Regulation of gene expression, enzyme activities, and impact of genetic variation. Pharmacol Ther 2013;138:103-41. 